\title{
Lean Planning \& Production Flow Analysis through Lean Techniques: A Steel Sector Case Study
}

\author{
Authors \\ Krishna Chandra Mishra ${ }^{1}$, Er. Vivek Khokhar ${ }^{2}$ \\ ${ }^{1}$ M.Tech Scholar, GITAM, Jhajjar, Haryana \\ ${ }^{2}$ Head of Department, Mechanical Engineering, GITAM, Jhajjar, Haryana \\ Email- mech.kcmishra@gmail.com
}

\begin{abstract}
:
The lean thinking is a conceptual approach that has an enormous impact in the field of manufacturing sector. It started in the automobile industry and has since been widely applied more than frequent in different sectors of process industry. This notion has been discussed in an introductory portion. In this article, We have discussed the issue of lean manufacturing in the steel sector by case study. This study considers how the lean technique necessary for demand driven product flow may be implemented in steel sector with the help of cyclic schedules. Value stream mapping (VSM) is one of the key lean tools used to identify the opportunities for various lean techniques with the help of cyclic schedules. This is the lean planning which has been used in steel sector to identify the hidden waste and source of waste. A current state map is drawn to analyze the route of production flow in the steel industry. Then a future state map is drawn to design a lean process flow with the help of lean planning through the process improvement. This case study demonstrates the importance of Value stream mapping (VSM) technique in lean planning and discusses the application of lean manufacturing in a steel sector.

Keywords: Cyclic schedules, Lean manufacturing, Lean planning, Steel sector, Value stream mapping (VSM).
\end{abstract}

\section{INTRODUCTION}

Lean starts from the refusal to accept waste. Lean Production is an adaption of mass production in which work is accomplished in less time, in a smaller space, with fewer workers, with less equipment, and yet achieves higher quality level in final product. Since the evolution of Toyota Production System in 1950s, the lean movement has been widely accepted in automobile industry. However, extensions to the process industries (steel sector) has been much slower. For removing the obstacles like resource complexity, the notion of the point of discretization for the process industry has been explained by Abdulmalek et al.(2006). This notion is based on the fact that in production flow route map existing in process industries there is a point where process production turns into discrete production. For removing the wastes existing in production flow route map, different lean techniques like SMED and total productive maintenance (TPM) have become very useful. In lean planning, cyclic schedules ("Heijunka") have played a very important role for synchronizing subsequent nondiscrete production stages. Cyclic schedules help to detect disturbances earlier and reduce set up time and included costs. Cyclic schedules help for enhancing continuous improvement activities and supply chain coordination, as planners and operators as well as suppliers and customers get acquainted to the fixed schedule. The focus of lean approach is on cost reduction through eliminating non value added activities existing in the production flow route map. In lean 
manufacturing, there are several forms of wastes like defects, overproduction, transportation, waiting, inventory, motion, and processing. These all types of wastes are eliminated through Muda (waste elimination) lean technique. Value stream mapping (VSM) is the key lean tool used to identify the hidden waste and the source of waste existing in the production process. Lean application in any industry is guided by 5 simple steps starting from identifying the value of process, identifying the process value stream, focusing on the process flow, configurations on the pull factor and work towards process perfection . Lean planning is done based on these 5 steps of lean application in any industry. Different types of lean tools such as Kanbans, Total Productive Maintenance (TPM), set up time reduction, Total Quality Management (TQM), 5S and VSM has been used by the project team. A collection of all these lean tools are required to identify the sources of wastes and to eliminate wastes existing in the production process of any industry. This case study is very useful for the process industry to determine how different types of lean tools with the help of lean methods and lean approaches are used to maintain better inventory control, identify sources of waste, eliminate waste, improve product quality, reduce cost, and capable of better process control. This case study approach implemented in steel sector is a project based on lean methodology. The objective of this case study based project is to determine how lean tools are utilized to increase the performance of the process industry by eliminating wastes and non-value added items and actions.

\section{CASE STUDY}

The steel industry is often considered an indicator of economic progress, because of the critical role played by steel in infrastructural and overall economic development. The major production units in steel (process) industry are as follows:

- Raw Material Handling Plant (R.M.H.P.)

- Coke Oven and Coal Chemical Plant (C.O. \& C.C.P.)
- $\quad$ Sinter Plant (S.P.)

- Blast Furnace (B.F.)

- Steel Melting Shop (S.M.S.)

- Continuous Casting Department (C.C.D.)

- Light and Medium Merchant Mill (L.M.M.M.)

- Medium Merchant and Structural Mill (M.M.S.M.)

- Wire Rod Mill (W.R.M.)

Now, The production flow route map in steel industry can be discussed in the following manner

\subsection{Raw Material Handling Plant (R.M.H.P.)}

The Raw Material Handling Plant (R.M.H.P.) receives the basic raw materials required for the steel making process from various sources through railway wagons and by road. These raw materials are stacked by stackers and reclaimed by reclaimers and distributed to various other departments of steel industry. The Iron Ore Fines, Iron Ore Lump, Sized Iron Ore, Limestone (B.F. \& S.M.S. grades), Dolomite (B.F. \& S.M.S. grades), Sand, Quartzite and Manganese lumps are stacked at Ore \& Flux Yard. The Imported Coking Coal (I.C.C.), Medium Coking Coal (M.C.C.), Boiler Coal (B.C.) are stacked in Coal Yard. Coke is sent directly to Blast Furnace after tippling from ore and flux wagon tipplers. These raw materials are sent to various departments as indicated below:

- Sinter Plant : Iron Ore Fines, Lime stone (B.F.), Dolomite, Sand and LD slag.

- Blast Furnace : Sized Iron Ore, LD slag, Manganese Lump, Quartzite and Coke.

- Steel Melt Shop : Dolomite (S.M.S.), Sized Iron Ore.

- Thermal Power Plant (T.P.P.) : Crushed Boiler Coal.

- Coke Ovens (C.O. \& C.C.P.) : Imported coking coal (ICC), Medium coking coal (MCC).

\subsection{Coke Oven and Coal Chemical Plant (C.O.} \& C.C.P.)

Blast Furnaces, the mother units of any Steel Plant require huge qualities of strong, hard and porous solid fuel in the form of hard metallurgical coke for supplying necessary heat for carrying out the 
reduction and refining reactions besides acting as a reducing agent.

Coke is manufactured by heating of crushed coking coal (below $3 \mathrm{~mm}$ ) in absence of air at temperature of $1000 \mathrm{C}$ and above for about 16 to 18 hours. A Coke Oven comprises of two hollow chambers namely coal chamber and heating chamber. In the heating chamber a gaseous fuel such as Blast Furnace Gas, Coke Oven Gas etc., is burnt. The heat so generated is conducted through the common will to heat and carbonize the coking coal placed in the adjacent coal chamber. Red Hot coke is pushed out of the oven and sent to Coke Dry Cooling Plants for cooling to avoid its combustion. The Coal chemicals such as Benzoyl (and its products), Tar (and its products) Ammonium Sulphate etc., are extracted in Coal Chemical Plant from Coke Oven gas. After recovering the coal chemicals the gas is used as a byproduct fuel by mixing it with gases such as BF Gas, LD Gas etc. A mechanical, biological and chemical treatment plant takes care of the effluents.

\subsection{Sinter Plant}

Sinter is a hard and porous ferrous material obtained by agglomeration of Iron Ore fines, Coke breeze, Lime Stone fines, Metallurgical wastes viz., Flue dust, Mill scale, LD slag etc. Sinter is a better feed material to Blast Furnace in comparison to Iron Ore lumps and its usage in Blast furnaces help in increasing productivity, decreasing the coke rate and improving the quality of hot metal produced. Sintering is a process of Agglomerating iron ore fines into a porous mass by incipient fusion caused by combustion with in the mass of the ore particles. Various raw materials used in sintering process are as follows:
i) Iron ore fines $(0-10 \mathrm{~mm})$
ii) Coke - used as fuel
iii) Limestone \& Dolomite - to maintain required sinter basicity

iv) Sand - to maintain required sinter basicity

v) Metallurgical wastes - to use wastes effectively and thus reduce the cost of sintering

vi) Lime - to enhance the process of sintering

\subsection{Blast Furnace (B.F.)}

Hot Metal (pig iron) is produced in Blast Furnaces, which are tall vertical furnaces. The furnace is named as Blast Furnace as it is run with blast at high pressure and temperature. Raw materials such as sinter/iron ore lumps, fluxes (limestone/dolomite) and coke are charged from the top and hot blast at $1100^{\circ} \mathrm{C}-1300^{\circ} \mathrm{C}$ is blown almost from the bottom. The steel making process starts with mixing iron ore, limestone and coke (made from coal) in a blast furnace and heating to temperatures of over $1100^{\circ}$ by blasts of hot air using the carbon in the coke as a reducing agent. Once in a molten state, the hot air removes oxygen and other impurities to produce molten iron (pig iron). In this process, the iron absorbs some carbon.

\subsection{Steel Melt Shop (S.M.S.)}

Steel is an alloy of iron with carbon up to $1.8 \%$ hot metal produced in Blast Furnaces contains impurities such as carbon $(3.5-4.25 \%)$, silicon $(0.4-0.5 \%)$, manganese $(0.3-0.4 \%)$, sulphur (.04\% max) and phosphorous $(0.14 \% \max )$ is not suitable as a common engineering material. The impurities should be eliminated or decreased by oxidation process to improve the quality of molten steel. The carbon is removed in steelmaking furnaces by mixing molten iron and scrap to produce steel of the desired carbon contents. There are different types of steel making furnaces; these include the basic oxygen furnace, openhearth furnace and electric arc furnace. Now a days, In steel industries top blown Basic oxygen furnaces/converters called L.D. Converters (L \& D stands for Lintz and Donawitz) are used for producing liquid steel. $99.5 \%$ pure oxygen is blown in the convertor through oxygen lance having convergent divergent copper nozzles at the blowing end. Oxygen oxidizes the impurities present in the hot metal, which are fixed as slag with basic fluxes such as lime.

\subsection{Continuous Casting Department (C.C.D.)}

Continuous casing may be defined as teaming of liquid steel in a mould with a false bottom through which partially solidified ingot/bar (similar to shape and cross section of the mould) is 
continuously withdrawn at the same rate at which liquid steel is teamed in the mould. Facilities at a continuous casting machine include a lift and turn table for ladles, copper mould, oscillating system, tundish, primary and secondary cooling arrangements to cool the steel bloom.

Liquid steel produced in LD convertors is solidified in the form of blooms in continuous bloom casters. Entire quantity of molten steel produced $(100 \%)$ is continuously cast in radial bloom casters. Blooms produced in Continuous Casting Department do not find much applications as such and are required to be shaped into products such as billets, rounds, squares, angles (equal and unequal) channels, I-PE beams, HE beams, wire rods and reinforcements bars by rolling them in three sophisticated high capacity high speed.

\subsection{Hot Rolling Mills}

Blooms obtained from continuous casting department of Steel Melting Shop are used to cut the billet length in Light and Medium Merchant Mill (L.M.M.M.). Both shapes blooms (long pieces of steel with square cross section) and billets are known as semi finishes steels. Blooms obtained after continuous casting department having square section of $250 * 250 \mathrm{~mm}$. are dispatched to Medium Merchant and Structural Mill (M.M.S.M.). In Medium Merchant and Structural Mill (M.M.S.M.) the billets having cross section of $250 * 250 \mathrm{~mm}$. as a feed material are heated to rolling temperatures of $1200^{\circ} \mathrm{C}$ in two walking beam furnaces each of rounds, squares, flats, angles (equal and unequal), channels, IPE beams/HE beams (Universal beams) having high strength and close tolerance for producing the finished material of steel like rounds, squares, flats, angles (equal and unequal), channels, IPE beams/HE beams (Universal beams). The other blooms having cross section of $250 * 320 \mathrm{~mm}$. obtained after continuous casting department are dispatched to Light and Medium Merchant Mill (L.M.M.M.). In Light and Medium Merchant Mill (L.M.M.M.), the billets having cross section of $250 * 320 \mathrm{~mm}$. are rolled into billets of $125 \times 125 \mathrm{~mm}$ size after heating them into two number of walking beam furnaces of 200 tons/hrs.

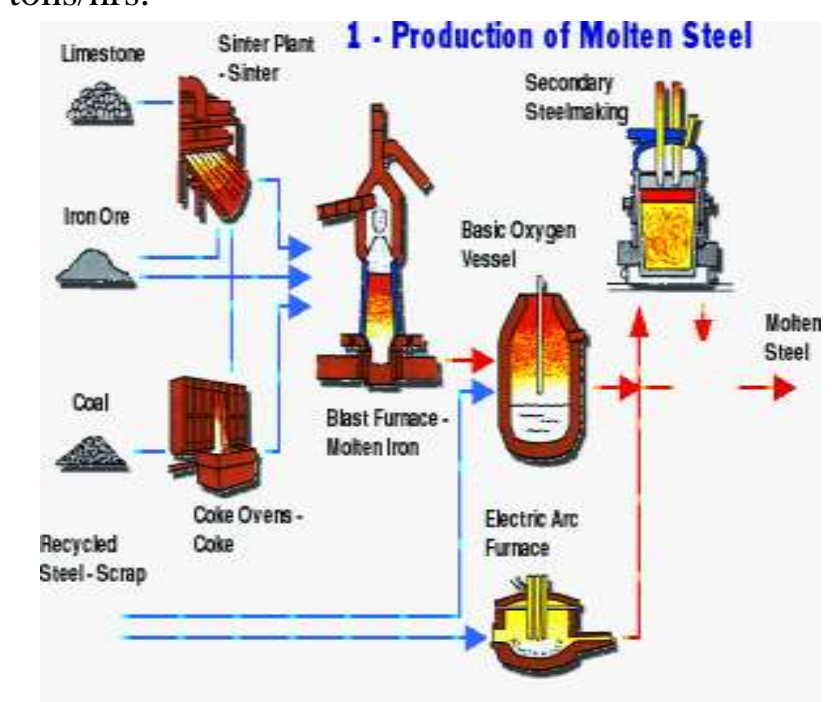

Figure 1: Production of Molten Steel in Steel Industry

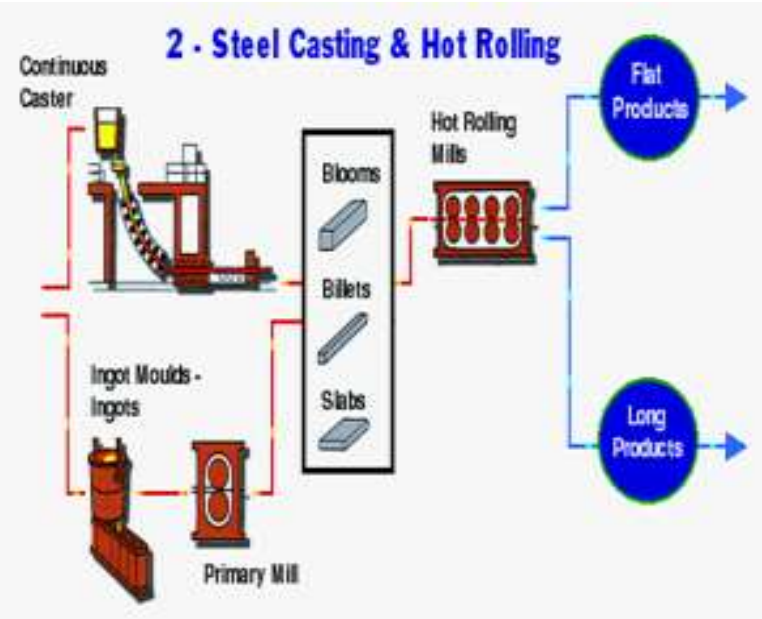

Figure 2: Production of Long \& Flat Products in Steel Industry

\section{LEAN PLANNING, ITS TOOLS AND METHODS}

\section{1: Lean Planning in Steel Industry with the help of VSM tool}

In recent era, Lean Planning has been widely accepted by leading manufacturing companies throughout the world. Leading automobile manufacturing industries have used lean planning as a major resource for eliminating waste and producing positive outcomes like reduction in cycle time, cost minimization, improvement in quality after deleting defects. The main focus of Lean planning is to achieve the same output with less input; such as less time, less space, less 
human effort, less machinery, less material and less cost. For increasing the understanding regarding lean manufacturing, we first need to understand the basic principles that guide it. Some major lean manufacturing principles are as follows: recognizing wastes, having standard processes, having a continuous flow, pullproduction, maintaining quality at the source and maintaining continuous improvement.

\section{2: Lean Tool: Value Stream Mapping}

For designing and implementing lean planning, Value stream mapping (V.S.M.), a lean manufacturing tool is used. Value Stream Mapping originated from the Total Productive Maintenance (T.P.M.), is known as "material and information flow mapping tool".

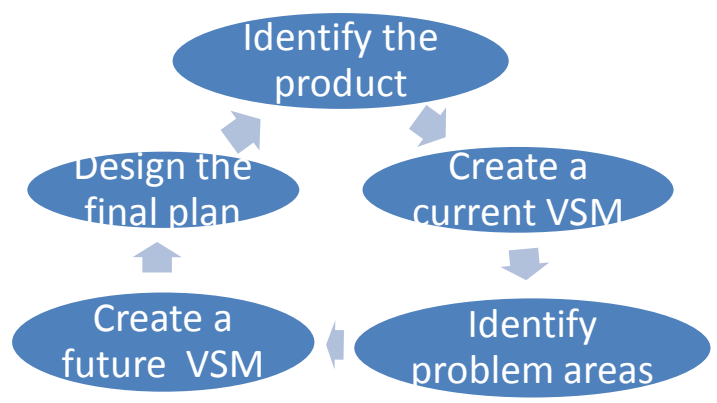

Figure 3: Value Stream Mapping Tool Thus, we can say that above 5 steps shown in figure are very important for the creation of VSM.

\section{3: Lean Methods necessary for the creation of VSM}

Different methods of lean planning required for the creation of value stream map are as follows:

- Takt Time

- Just-In-Time

- Total Productive Maintenance (TPM)

- Gemba

- Kaizen Initiatives

- Cycle Time

- Data of Changeover time

- Cyclic Schedules

These different lean methods are used for creating the value stream map of steel industry. Based on the current state map (Conventional Blast furnace route) of steel industry the production flow and material flow is analyzed. After analysis non value added activities and wastes are identified existing in the conventional (Blast furnace) production flow route map of steel industry.

3.4: Current state Map (Conventional Blast furnae route consisting of Sinter Plant \& Coke Ovens) of Steel Industry

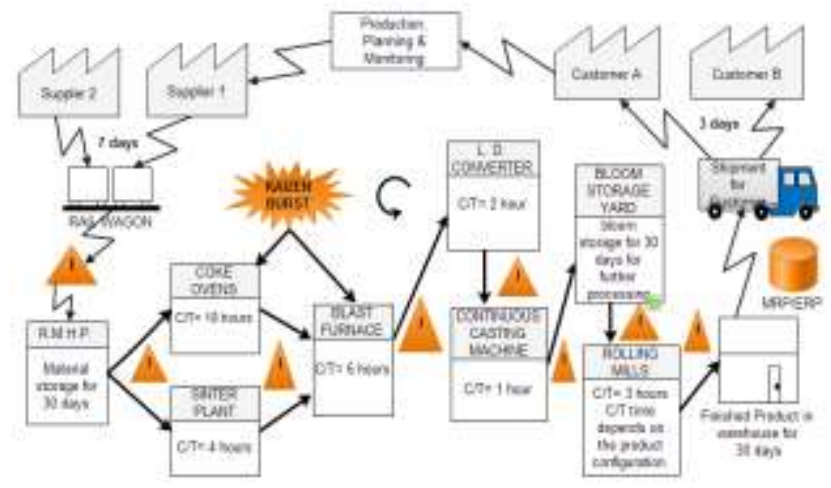

Figure 4: Current State Map (Conventional Production flow route map consisting of blast furnace, coke oven and Sinter Plant)

Lead Time Calculation $=7$ days +19 hours +4 hours +6 hours +2 hours +1 hour +3 hour +3 days $=$ 11 days $\& 11$ hours

This current state map in figure 4.16 , describes the conventional process of the steel industry.

\section{5: Corex Process}

The Corex Process is a smelting reduction process created by Siemens VAI as a more environmentally friendly alternative to the blast furnace. Presently, the majority of steel production is through the blast furnace which has to rely on ever decreasing amounts of coking coal. That is coal which has been cooked in order to remove impurities so that it is superior to coal. In addition, the Blast furnace requires a sinter plant too in order to prepare the iron ore for reduction. Unlike the Blast Furnace, smelting reduction processes are typical smaller and use coal and oxygen directly to reduce iron ore into a usable product.

The Corex process consists of two main parts a Reduction Shaft and Melter- Gasifier. The main reagents for the Corex process are iron ore, noncoking coal, and oxygen. Unlike the Blast furnace the Corex process does not use a hot blast of nitrogen, thereby greatly reducing NOx gas emissions, but instead uses oxygen. In addition, the Corex process can use iron oxides containing 
up to $80 \%$ lump ore and uses non coking coal directly as a reducing agent.

In the Reduction shaft the iron ore, along with limestone and dolomite additives, is added and then reduced by reduction gas into $95 \%$ direct reduced iron, DRI. The DRI is then redirected via six discharge screws into the melter-gasifier. The Melter- Gasifier has three main sections, the gaseous free board zone, the Char bed, and the hearth zone, and it has an effect on several stages in the process. First it serves to create the reduction gas by gasifying the coal with oxygen and then cooling it. After being reduced, the DRI is redirected to the char bed where the iron and slag are melted and then directed to the hearth zone. The heat inside the metal gasifier keeps the amount of phenols small, keeping them out of the atmosphere. Meanwhile, carbon monoxide and hydrogen gas from the original gasification of the coal exit the gasifier while other by-products are captured in the metallic slag. The rest of the hot gas is then cooled and sent into the reduction shaft resulting in the Corex export gas which is used to control pressure in the plant. The corex process described in Figure 5

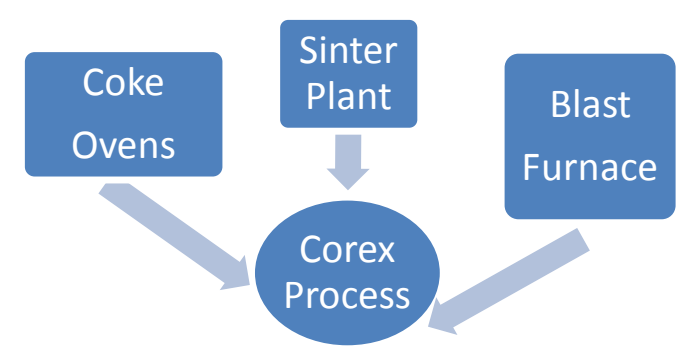

Figure 5: Corex Process Layout

3.6 : Future state Map of Steel Industry equipped with latest technology (Corex process):

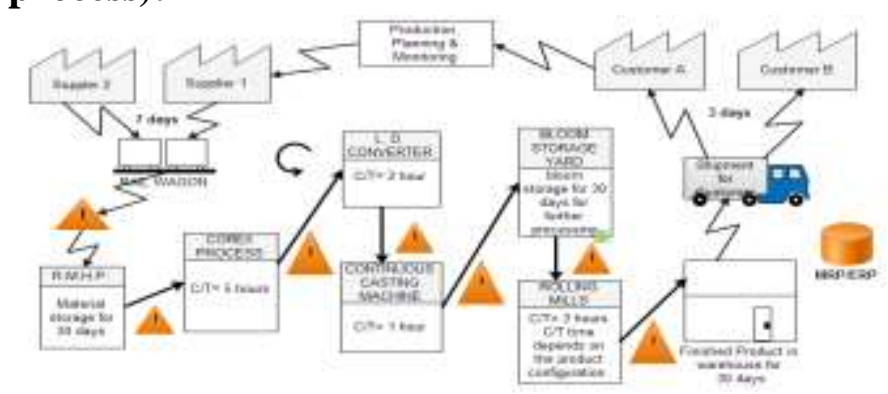

Figure 6: Future State Map (Steel Industry equipped with latest technology i.e. Corex Process)
Lead Time Calculation $=7$ days +5 hours +2 hours+ 1 hour+ 3 hours+ 3 days= 10 days $\& 11$ hours

It means steel production with the help of corex process takes less lead time than conventional route of blast furnace consisting sinter plant and coke ovens without changing the time of work in progress inventory. Therefore Corex process described in figure 4.18 with the help of future state map (Latest technology) is more efficient than Blast- furnace consisting of sinter plant \& coke ovens (conventional method).

\section{GAIN AFTER IMPLEMENTATION OF VALUE STREAM MAPPING}

The goal of this section is to identify the potential gain after implementation of Value Stream Mapping with the help of modern technology like Corex process over conventional production flow route map of consisting of Blast furnace, Sinter Plant \& Coke Ovens. The project team has focussed on different manufacturing techniques which are as follows:

- Reduction in lead time

- Improvement in takt time

- Value stram mapping

- Work in Progress (WIP)

\section{1: Improvement in Cycle Time}

The cycle time of a machine is calculated by adding man time and machine time. Cycle time affects the capacity output of the machine. The cycle time of blast furnace consisting sinter plant, coke ovens and corex process has been calculated and described in figure 7

\section{Cycle Time in Hours}

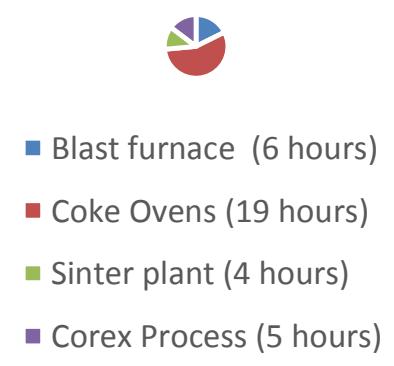

Figure 7: Cycle Time Comparison between Blast furnace \& Corex Process 
As, we have seen that the cycle time of conventional production flow route map (consisting of blast furnace, sinter plant and coke ovens) is 29 hours. While, cycle time of Corex process is only 5 hours. So, Corex process is more efficient than conventional process of Blast furnace.

\section{2: Improvement in Value-added Time}

The total value added time of conventional method (Blast furnace consisting sinter plant and coke ovens) is 35 hours and the total value added time for corex process is only 11 hours. So, the value added time in case of modern technology (corex process) has been improved by 24 hours. Figure 8 tells about the comparative analysis of Value-added time.

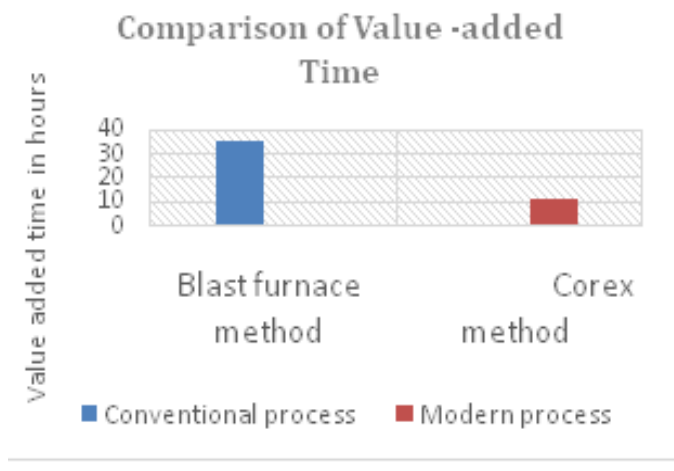

Figure 8 : Value Added Time Comparison $b / w$ Blast furnace consisting Sinter Plant, Coke Ovens $\&$ Corex Process

\section{3: Improvement in Takt Time}

"Takt Time" is known as the rate at which customers are buying products from the production line. So, Takt Time is the unit production rate that must be met to match customer requirements. The formulae for calculation of Takt time is as follows:

Takt Time $=$ Available work time per day

Suppose, the demand for the Wire Rod coil steel products is an average of 6,000 tons per month. Now we assume that steel industry runs for 30 days per month. So, the average daily requirement is $6,000 / 30=200$ tons per day. The average Wire Rod coil weight is 2 tons, so this translates to approximately $200 / 2=100$ coils per day. Steel industry continuously runs for three shifts per day, which means 1,440 working minutes per day. So Takt Time is 14.4 minutes per coil.
Takt time $=\frac{24 \mathrm{hrs} . * 60 \mathrm{~min} / \mathrm{hr}}{100}=14.4 \mathrm{~min}$

This Takt time does not indicate that a coil has to be made in 14.4 minutes, but rather than one must be completed in every 14.4 minutes on average. Customer demand is met in 14.4 minutes, but the process time is dependent upon the sum of process times at each workstation.

Now, we take the case of conventional system (Blast furnace) of steel industry. Conventional system takes more time for producing the hot metal. Then, this hot metal is sent to L.D. Converter. So, to produce hot metal from conventional route of blast furnace takes more time. So, In this case customer's demand may not be fulfilled also.

But, to produce hot metal from Corex process takes less time. After the production of hot metal, it sent to L.D. Converter. So, customer's demand is met if hot metal is produced with the help of latest technology.

This is the also the main advantage of Corex process over blast furnace consisting sinter plant $\&$ coke ovens.

\section{5: Process Improvement in Project}

With the help of Kaizen the Coke oven, Sinter plant and blast furnace set up has been replaced by Corex process. This is the type of Process improvement in steel industry.

\section{CONCLUSION}

The use of the Value Stream Mapping (VSM) improved the approach in Lean Planning initiatives as it reveals obvious and hidden waste that affected the productivity steel industry. There is a significant amount of the time products spent on the production system usually was waiting and non-value added. Quantitative evidence showed that many of the Lean tools have an expected impact related to the reduction of this waiting time. The evaluation of these improvements through the use of the cycle time evaluation highlights the economic impact of time improvements. The Value Stream Mapping (VSM) applied to assess the expected impact of a change in the production process resulted in 
savings (lower rejection rates) and to a certain extent, a positive view was due to the fact that there were substantial gaps between standardized work and real work.

\section{REFERENCES}

1. Womack, J.P., Jones, D.T., Roos D.,1990. The Machine that changed the World. Free Press, New York, NY.

2. Womack, J.P., Jones, D.T., Roos D.,1990. The Machine that changed the World. Free Press, New York, NY.

3. Groover, M. P. (2008). Automation, Production Systems and ComputerIntegrated Manufacturing. New Jersey, NJ: Pearson Education, Inc.

4. Abdulmalek F. A., Rajgopal, J., Needy, K.L., 2006. A classification scheme for the process industry to guide the implementation of lean. Engineering Management Journal 18 (2), 15-25.

5. Melton, T., 2005, The benefits of lean manufacturing-what lean thinking has to offer the process industries. Chemical Engineering Research and Design 83, 662673.

6. Van Donk, D.P., Van Dam, J.P., 1996. Structuring complexity in scheduling: a study in the food-processing industry. International journal of Operations and Production Management 16 (5), 54-63.

7. Glenday, I., 2006. Breaking Through to Flow, Lean Enterprise Academy, Ross-onWye, UK.

8. King, P. L., 2009. Lean for the process Industries-Dealing with Complexity. Productivity Press. New York, NY.

9. Pool, A., Wijngaard, J., Van der Zee, D. J., 2011. Lean planning in the semi-process industry, a case study. Int. J. Production Economics 131, 194-203.

10. Rahani, A. R., Ashraf, M. A., 2012. Production Flow Analysis through Value Stream Mapping: A Lean Manufacturing Process Case Study. Procedia Engineering $41,1727-1734$. 